\title{
Dr. Glaus kehrt zurück
}

Daniel Schlossberg

Korrespondenz:

Dr. med. Daniel Schlossberg Bachmattstrasse 53 CH-8048 Zürich

daniel.schlossberg[at]hin.ch
Der letzte Hausarzt der Schweiz übernimmt seine Praxis wieder. Die Chinesen haben sich verabschiedet. Sie erinnern sich: Dr. Glaus liess sich pensionieren und übergab seine Praxis den modernen Raubrittern des Gesundheitswesens - mangels Alternativen, versteht sich.

Doch nun ist das Geschäft mit den Eiseninfusionen und anderen Blockbustern moderner Gesundheitszentren ins Stocken geraten. Dunkel verfärbte Haut in den Ellbeugen, anaphylaktische Reaktionen und trotz Eisen à discrétion weiterhin müde junge Damen haben die Nachfrage einbrechen lassen.

Dr. Glaus hat mittlerweile beide Katarakte beheben lassen und mithin an Sehschärfe und Einsicht gewonnen. Er hat sofort wieder regen Zulauf in seine Praxis. Er erklärt den jungen müden Damen die Prinzipien der Entschleunigung, den Dicken die der Entschlackung. Wer seine Praxis betritt, dessen Smartphone versagt unverzüglich den Dienst: Es wird automatisch stumm geschaltet. Dr. Glaus hat dafür gesorgt, dass im Wartezimmer sitzende Ratsuchende auf sich selbst zurückgeworfen werden. Sie besinnen sich dort ihrer tatsächlichen Probleme und sie entdecken, dass ein Problem wie weggewischt ist: ihre ubiquitäre, fast schon universelle Erreichbarkeit und Verfügbarkeit. Kein Chef, der nachfragt, wo man verblieben sei, kein eifersüchtiger Partner, der einem nachspioniert. Und selbst der NSA kommt an keine

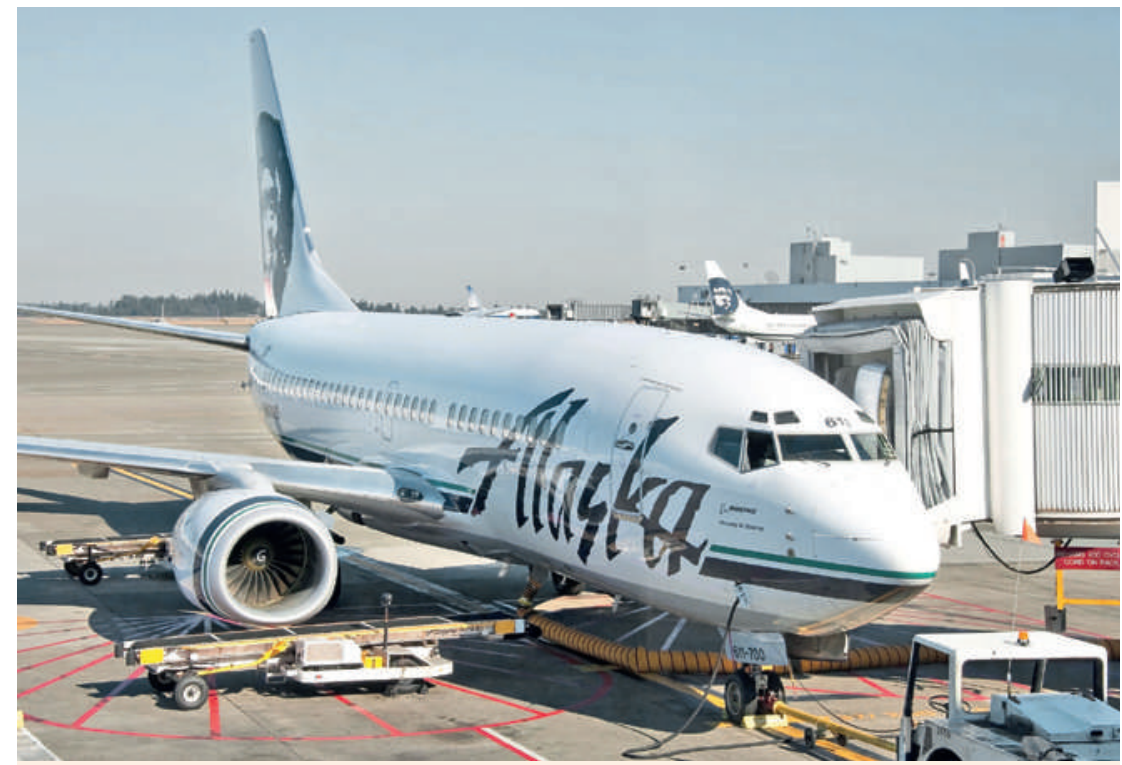

Nach einem Revival als Hausarzt in eigener Praxis sucht Dr. Glaus - mittlerweile AHV-Bezüger und völlig erschöpft - Ruhe in Alaska. persönlichen Daten ran. Die orwellsche Horrorvision von 1984, längst von der Realität eingeholt und übertroffen, löst sich im Äther auf, und plötzlich fühlt man sich nicht mehr verfolgt, gehetzt und gestresst. In Dr. Glaus' Wartezimmer kehrt eine innere Ruhe in die, die dort sitzen, und manche wissen, nach gebührender Wartezeit im Sprechzimmer angelangt, ihren Konsultationsgrund kaum noch. So kann sich Dr. Glaus den tatsächlichen Problemen widmen, die die Menschen ausserhalb des Paradieses ereilen.

Jetzt kommen wirklich Kranke in die Praxis, die es zu diagnostizieren und $\mathrm{zu}$ behandeln gilt. Und nicht jene mit diffusen Befindlichkeitsstörungen, die Opfer eines bösen Zeitgeistes geworden sind. Dr. Glaus übt nun wieder jenen Beruf aus, den er erlernt hat: Mit diagnostischer Schärfe, therapeutischen Konzepten und mit einem gerüttelt Mass an Empathie begegnet er seinen Patienten. Das Idyll der wiedererfundenen hausärztlichen Praxis ist perfekt!

Nur - Dr. Glaus ist mittlerweile AHV-Bezüger, und eines Tages verlassen ihn seine Kräfte. Er wird mit einem Schlag selbst zum Patienten und nach gelungener Behandlung seines Leidens im Akutspital und kurzer Rehabilitation kehrt er nach Hause zurück. Er sucht nach einem Hausarzt und findet keinen, nur sich selber. Der letzte Hausarzt muss nun kürzertreten. Seine Patienten holen ihre Akten und werden nun in grossen medizinischen Zentren eingescannt. Egal, wer sie dort sieht, der Zugriff auf ihre Krankengeschichte ist gewährleistet. Doch die intime Kenntnis ihrer Geschichte ist verlorengegangen. Und was nicht eingescannt worden ist, existiert einfach nicht. So einfach funktioniert die Brave New World. Und die jungen Ärzte, angestellt von börsenkotierten Unternehmen, einfachen Aktiengesellschaften, profitorientierten Investmentgesellschaften und so fort, diese jungen Ärzte legen pünktlich Arztkittel, Tablet und Maus auf die Seite, jetzt ist es Zeit für das andere Leben der Generation Y.

Dr. Glaus beschliesst, nach Alaska in den kanadischen Teil auszuwandern. Er kauft sich die gesammelten Werke von William S. Burroughs, der jetzt seinen 100. Geburtstag hätte feiern können. Dieser Rebell unter den Literaten hat es ihm angetan, vielleicht wäre er auch ein Süchtiger geworden, hätte er nicht andere von deren Sucht befreien sollen. Gelungen ist ihm das in seltenen Fällen. Jetzt will er studieren, woran es gelegen haben mag. Dr. Glaus wird sich vielleicht aus Alaska vernehmen lassen, wenn weitere Einsichten gereift sein werden. 